\title{
Inhibitory control of reaching movements in humans
}

\section{Giovanni Mirabella $\cdot$ Pierpaolo Pani $\cdot$ Martin Paré $\cdot$} Stefano Ferraina

Published online: 14 February 2009

(C) Springer-Verlag 2009

\section{Erratum to: Exp Brain Res (2006) 174:240-255}

DOI 10.1007/s00221-006-0456-0

In the published original version of the article, two equations have been inverted.

The equation on page 243 (left column, section "Data analysis") should appear on page 247 (left column, section "Behavioral estimate of reaching movement cancellation") and vice versa.

The online version of the original article can be found under doi:10.1007/s00221-006-0456-0.

G. Mirabella $\cdot$ P. Pani $\cdot$ M. Paré $\cdot$ S. Ferraina $(\bowtie)$

Department of Human Physiology and Pharmacology,

University 'La Sapienza', Piazzale Aldo Moro 5,

00185 Rome, Italy

e-mail: stefano.ferraina@uniroma1.it

P. Pani

Dottorato di Ricerca in Neurofisiologia,

University 'La Sapienza', Piazzale Aldo Moro 5,

00185 Rome, Italy

M. Paré

Department of Physiology, Queen's University,

Kingston, ON K7L 3N6, Canada 